\title{
PIPING ERECTION CONSTRUCTABILITY ISSUES IN A SEMI- AUTOMATED ENVIRONMENT (FIELD OPERATIONS PHASE)
}

\author{
Dr. Deborah J. Fisher, Assistant Professor \\ Dept of Industrial Engineering \\ University of Houston \\ Houston, TX 77204-4812 \\ and \\ Dr. James T. O'Connor, Assistant Professor \\ Dept. of Civil Engineering \\ University of Texas at Austin \\ Austin, TX 78712
}

\begin{abstract}
This research endeavor focuses on how semi-automated piping construction for process plants may become both technically and economically viable through constructability enhancement. This paper answers the question regarding how field operations need modifying in order to support the automated field effort and thus achieve the overall success objective. The semi-automated environment of piping erection assumes a Pipe Manipulator attached to the boom of a 22-ton rough-terrain crane for the base piece of pipe lifting equipment. The scope of this study is the analysis of horizontal piping erection. Three major categories of constructability issues are addressed in detail. These issues are material handling, equipment/tools capabilities, and equipment/tools configurations. Quantitative analysis methods include physical modeling and computer simulation, via a 3D CAD simulation software package. Constructability analysis results in a total piping erection savings of $24 \%$.
\end{abstract}

\section{Background}

This study is concerned with the activity of piping construction, and its potential for productivity improvement through automation. The Business Roundtable's "Construction Industry Cost Effectiveness Report" stated that piping is the most inefficient and single largest cost element of major industrial construction projects. It also stated that the task of piping construction is one of three areas having the highest potential for technological advancement [Business Roundtable 1982, 1].

Constructability analysis is performed, in order to develop "rules of thumb" that suggest specific practices to produce a more efficient piping erection operation. Constructability underscores the importance of up-front decisions during project planning, design, and procurement in support of the construction effort. Constructability is a key objective for achieving project success, particularly for projects involving some degree of automation [O'Connor and Fisher 1988, 185].

The semi-automated pipe lifting system assumes a Grove Pipe Manipulator attached to the boom of a 22-ton crane as the base piece of equipment for piping erection. The design specifications for the Pipe Manipulator were developed by DuPont and submitted to Grove for fabrication in 1980.

Research analysis is built on previous findings from studies performed by Glass at the University of Texas at Austin in 1984 [Glass 1984]. Glass compared the productivity of the Pipe Manipulator with conventional piping erection using a small, 15-ton hydraulic "Cherry Picker". Glass' findings, from over 55 hours of accurate, objective time-lapse film, indicated that the Pipe Manipulator was superior to conventional piping erection when lifting large diameter, vertical and bent pipe configurations. Horizontal piping erection by the Pipe Manipulator was not nearly as effective, and the Cherry Picker in this instance, outperformed the Pipe Manipulator, by a factor of 2 . 


\section{Methodologies}

The first step in this study was the identification of constructability issues for an automated piping construction system. The quantitative analysis methods of cycle time analysis, physical modeling, and computer simulation were then applied for constructability issue analysis.

\subsection{Constructability Issue Identification}

Through a review process with industry representatives from two contractors and one owner, and through brainstorming with faculty members from the University of Texas at Austin, three constructability issues for the field operations phase of piping construction were identified [Fisher and O'Connor 1988]. These issues, along with their corresponding sub-issues, are listed in Table 1.

Table 1 -- Quantitative Analysis Cycles for Constructability Issues

\begin{tabular}{|c|c|c|}
\hline $\begin{array}{l}\text { CONSTRUCTABILITY } \\
\text { ISSUE }\end{array}$ & $\begin{array}{l}\text { Physical } \\
\text { Modeling }\end{array}$ & $\begin{array}{l}\text { Computer } \\
\text { Simula- } \\
\text { tion }\end{array}$ \\
\hline $\begin{array}{l}\text { FIELD OPERATIONS PHASE } \\
\text { A. Material Handling } \\
\text { 1. Manipulator/Material Orientation } \\
\text { 2. Material Location } \\
\text { 3. Material Pick-up } \\
\text { 4. Interference } \\
\text { B. Equipment/Tools Capabilities } \\
\text { 1. Controls } \\
\text { a. Learning Curve Documentation } \\
\text { b. Operator Location } \\
\text { c. Desired Joint Motions and } \\
\text { Ranges } \\
\text { d. Booming vs Driving } \\
\text { e. Single-DOF vs Multi-DOF } \\
\text { 2. Path Planning } \\
\text { C. Equipment/Tools Configuration }\end{array}$ & $\begin{array}{c}15 \\
18 \\
23 \\
- \\
\\
15 \\
\text { all } \\
\text { all } \\
3 \\
\text { all } \\
- \\
\text { jaw config }\end{array}$ & $\begin{array}{l}15 \\
\text { all } \\
\text { all } \\
21 \\
\text { all } \\
* \\
-\end{array}$ \\
\hline
\end{tabular}

\subsection{Cycle Time Analysis}

future potential for operations research mathematical modeling

Data were collected by measuring the portion of the cycle time from when a piece of pipe is already gripped through when the pipe is lifted from the material cart and placed into the piperack. These are known as gross motions. This portion of the cycle represents about one-forth of the total piping erection effort, proving it to be a significant portion of the cycle to study. The portions of the piping erection cycle not modeled were when the Pipe Manipulator is staged and grips the pipe, when the Manipulator arm is returning to its original position, fine motion alignment ("feathering" the controls to get exact final alignment), idle time, jaw changing, respotting, and breaks. A percentage breakdown of each of these piping erection activities was determined from a combination of Glass' data and from time lapse film take-off's. 


\subsection{Modeling Methods}

A 3/8" scale plastic model was built of the crane, Pipe Manipulator, and piperack. The $0,0,0$ point of the cartesian coordinate system was selected to be the bottom left-hand corner of the piperack bay in which the pipe is being lifted. All variables were measured from this point. The plastic model was built to include measuring devices (protractors and tapes) for all eight degrees of freedom (DOF's) of the Manipulator. Data were collected for a total of 161 cycles with the plastic model.

The crane, Pipe Manipulator, and piperack were next modeled in a 3-D CAD simulation software package developed by Bechtel Eastern Power Corporation. This software, known as "Walkthru", contains on-line interference checking, and has the capability of recording and replaying object motions in real-time on demand so that the simulation of construction activities can be planned and analyzed. The piping construction elements were created on an Intergraph CAD system. The ASCII file format was then imported to a Silicon Graphics 4D workstation, on thich "Walkthru" was run. Figure 1 shows the computer model where the Pipe Manipulator is picking up a pipe from the material cart and placing it into the piperack. Data were collected from a total of 165 cycles taken on the computer model.

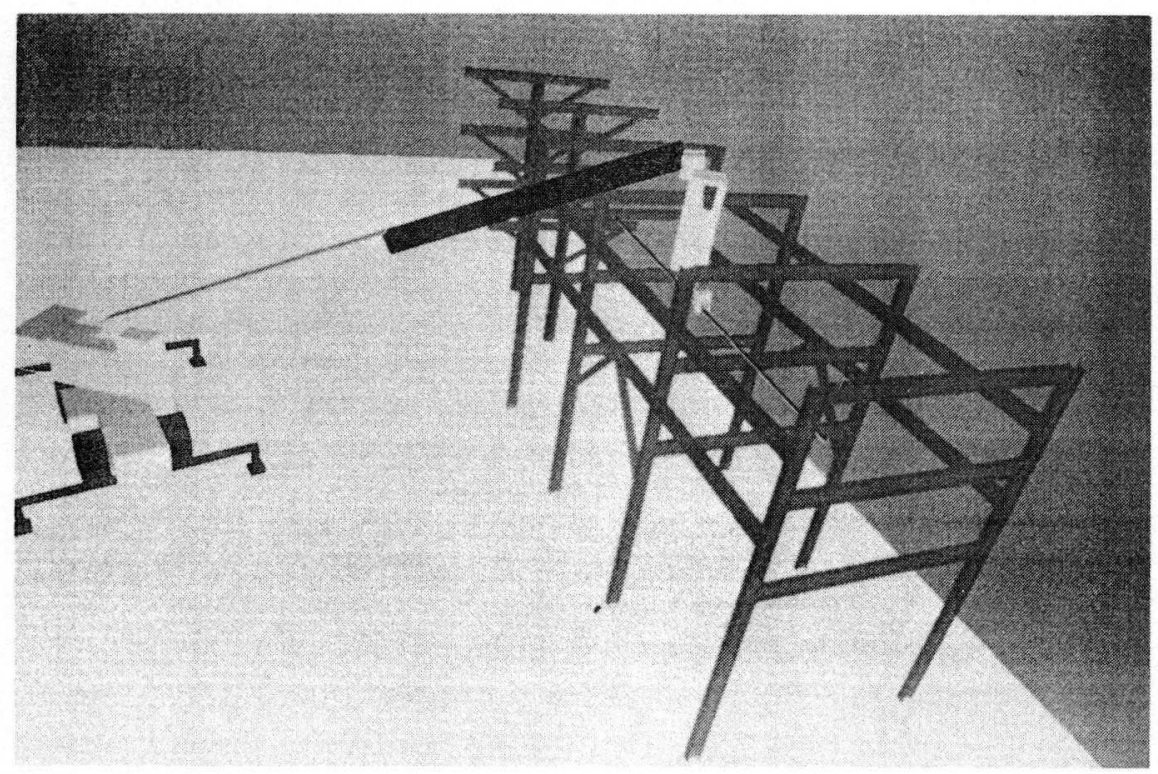

Figure 1 Computer Model of Pipe Manipulator Placing Pipe Into Final Position

\section{Data Analysis and Results}

This section reviews the results of the quantitative analysis methods of cycle time analysis, physical modeling, and computer simulation as they were applied to the constructability issues for the field operations phase of piping construction. Sensitivity analyses were summarized in the form of "spider web" diagrams (see Figure 2). These are diagrams containing the impact of cycle time (vertical scale) as a function of the percent of change of a variable (horizontal scale). The steeper the slope of the curve, the more sensitive is the variable. All sensitivity measurements for constructability issues are compared to "nominal conditions" as opposed to conditions observed from time lapse film 

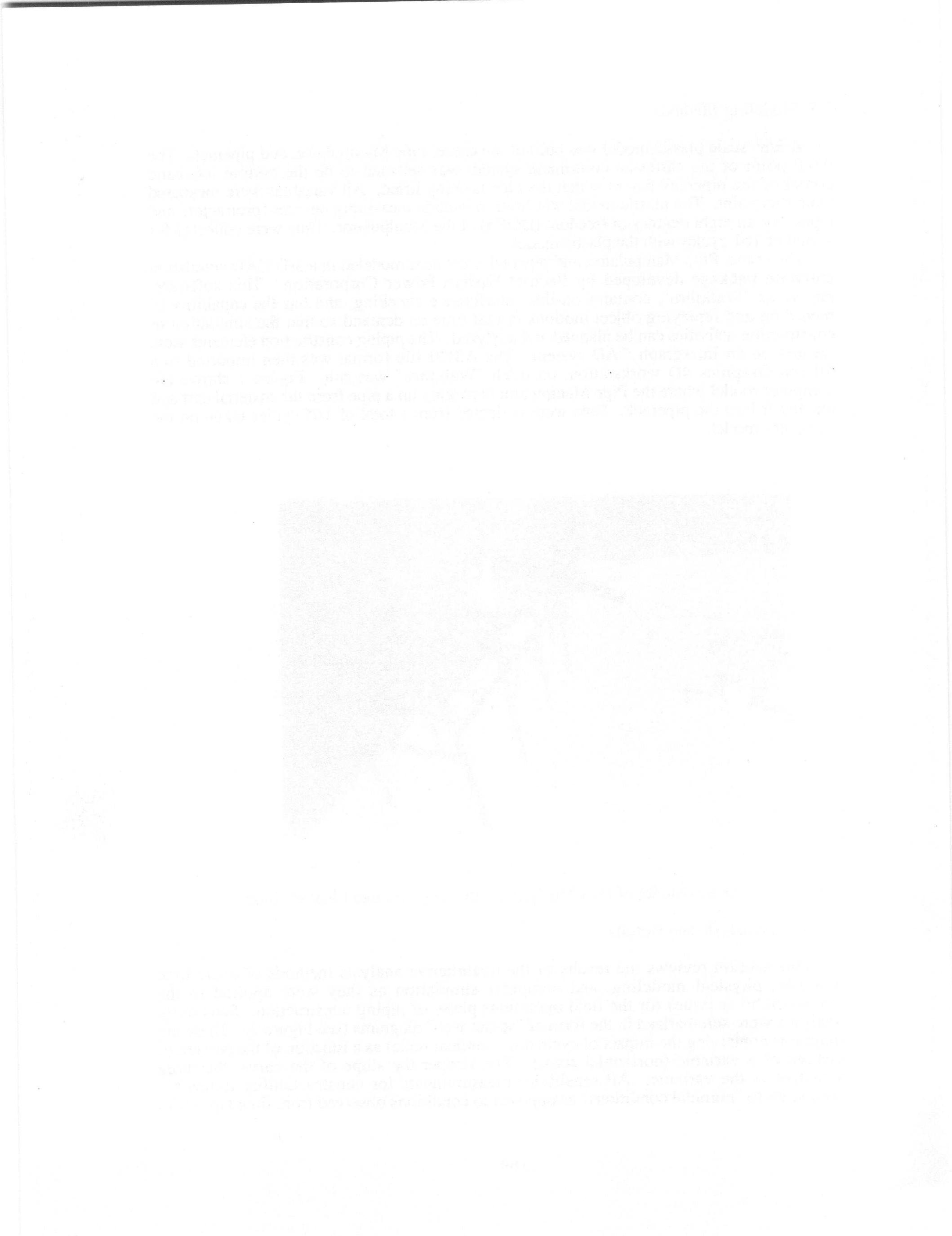
taken in Glass' study. The two differences in "nominal conditions" (more efficient) from "time lapse conditions" were that:

1) under "nominal conditions," the Manipulator was spotted in a position directly facing the piperack and pipe was spotted parallel and adjacent to the piperack (more efficient position), and

2) the Manipulator was driven forward in a "pick-and-carry" mode to place the pipe into the rack, rather than using a stationary "outrigger" mode requiring booming of the pipe into the rack (faster motion).

\subsection{Material Handling}

The constructability sub-issues of Manipulator spotting, Manipulator and materials orientation, material pick-up, and interference were quantitatively anayzed both with plastic modeling and computer simulation. Results of their sensitivity analyses indicate that Manipulator/materials orientation had the most significant cycle time impact. The curve for the plastic model shows a maximum cycle time increase of $108 \%$ and the computer curve shows a cycle time increase of $77 \%$ (see Figure 2).

\subsection{Equipment/Tool Capabilities}

The two general areas analyzed in this category are controls and Manipulator path planning. The subject of controls is broken down into the areas of learning curve, operator location, desired joint motions and ranges, booming vs driving, and single- vs multi-degree of fredom (DOF) controls. Of these sub-issues, operator location, booming vs driving, and single- vs multi-DOF controls had the most significant cycle time impact.

The Pipe Manipulator manufacturer indicated that joint motions of the machine could be increased significantly if the operator were removed from the control basket attached to the side of the crane boom [Smith 1988]. This is due to the fact that operator safety is no longer an issue. Not only did the increases in joint velocities cause an improvement in cycle time, but lessened basket interference also contributed. The total cycle time savings for both of these factors was $65 \%$ from computer simulations and $44 \%$ from plastic modeling. This savings plus the added advantage of increased lifting capacity of the Manipulator make control basket removal an attractive option.

Hydraulically extending the Pipe Manipulator boom is a very slow joint motion when compared to driving the Manipulator up to the piperack to place the pipe in the piperack. A cycle time savings of $49 \%$ resulted from computer simulations when the Pipe Manipulator was driven rather than boomed. Plastic model data indicated a $76 \%$ savings.

Single-DOF controls are the way the Manipulator is currently configured, which is to say that only one joint can be moved at a time. Multi-DOF controls mean that an operator can select several joint motions at one time, such as in the case of wanting to move the Manipulator in a straight line from the material cart to the rack by using boom lifting (radial motion) at the same time as boom extending (linear motion). This can be achieved by the use of joystick controls which imitate the more natural motions of a human being. A prediction of operator performance with multi-DOF controls (joystick) can be extrapolated from the plastic model, which is the closest simulation to a multi-DOF control system. During data collection there was a tendency to swing and pivot simultaneously, or lift and extend simultaneously, in order to intuitively anticipate the exact point where the end effector will land. A 25\% savings in the number of motions could potentially occur with the use of a multi-DOF control scheme when comparing the single-DOF computer simulation (one menu selection for each degree of freedom) to the multi-DOF plastic model. 


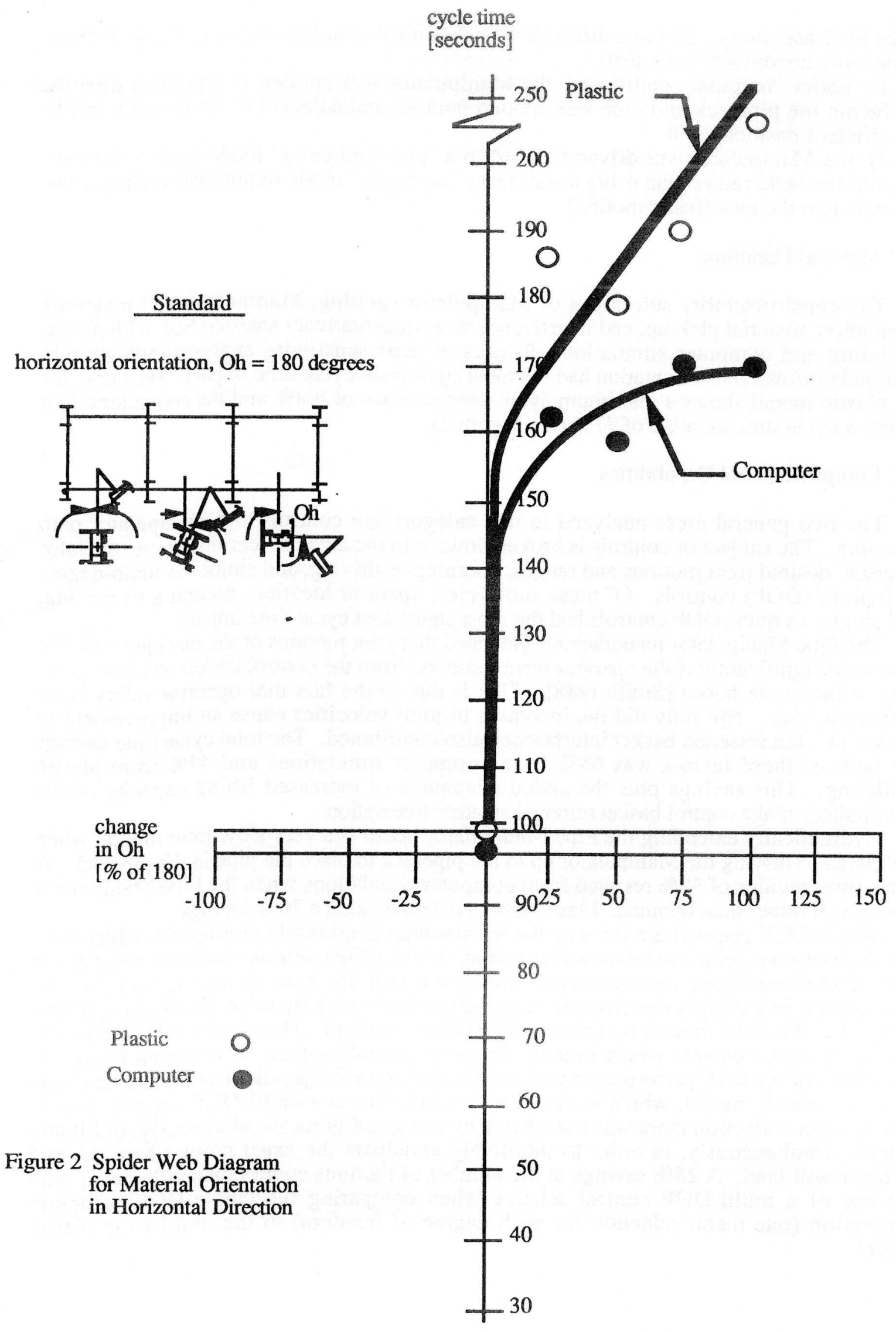




\subsection{Equipment/Tools Configuration}

The one Pipe Manipulator configuration change, that resulted from plastic modeling, was a slotted, scissor-action jaw design that eliminates the need to change jaws for different size ranges of pipe. In its current configuration, the Pipe Manipulator has four different jaw sizes [Glass 1984, 63]. The reduction to only one jaw would reduce the part of the cycle time spent changing jaws by $75 \%$.

\subsection{Summary}

From a summary of all sensitivy analyses, overall gross motion cycle time savings from "time lapse conditions" to "nominal conditions" were an average of $32 \%$ for computer simulation and plastic modeling combined. The constructability variables that influence this savings were the material handling issue of Manipulator/material orientation and the equipment capability issue of driving vs booming. An additional savings of $32 \%$ occured when going from "nominal" to "optimal conditions" (the best cycle time of all 161 plastic model cycles and all 165 computer model cycles). This savings was attributed to the equipment capabilities issues of operator location and single vs multi-DOF controls.

Another portion of the cycle time that was analyzed was the idle time portion of gross motion. A regression analysis was performed on time lapse data to correlate the number of gross motions with gross motion idle time. This was necessary due to the fact that idle time (operator communicating with crew, leaning out of basket to see, and deciding which controls to maneuver) was not simulated. The equation generated was utilized to predict what the gross motion idle time would be when going from "time lapse" to "optimal conditions". A predicted gross motion idle time savings of $90 \%$ for both computer simulation and plastic modeling was predicted and was attributed to the equipment capability issues of booming vs driving and single vs multi-DOF controls. Table 2 and 3 summarize these savings by erection activity and by constructability issue, respectively. Constructability issue savings in Table 3 were prorated based on the results of their individual sensitivity analyses.

Glass' research states that the 4-worker crew on the cherry picker was adequate (19\% idle time), but that the 3-member Manipulator crew contained $45 \%$ idle time on the time lapse film [Glass 1984]. Glass indicated that this idle time could be reduced to $17 \%$ by eliminating one of the crew members. This would bring idle time closer in line with conventional piping erection idle time

This crew balance savings, along with the percent savings from Table 3 , are incorporated into Glass' original productivity figures, resulting in Table 4. This table indicates that with constructability analysis and crew balancing, productivity is brought equal or better to the cherry picker for horizontal piping erection. Constructability analysis combined with crew balancing indicate that the Manipulator can perform $31 \%$ more productively $(0.96$ worker hours per lift vs 1.40$)$ than the cherry picker.

\section{ACKNOWLEDGEMENTS}

This work was funded by the National Science Foundation under grant number DMC8615105 and gratitude is expressed to the Foundation for its financial support. Gratitude is also expressed to Bechtel National, Inc. for their active participation and interest in this research. Gratitude is expressed to the DuPont Company for the use of its Pipe Manipulator. 


\section{REFERENCES}

Business Roundtable. Construction Technology Needs and Priorities. New York: The Business Roundtable, 1982. Construction Industry Cost Effectiveness Project, Report B-3.

Fisher, Deborah J. and James T. O'Connor. "Piping Erection Constructability Issues in a Semi-Automated Environment." In Proceedings for the International Pipe Association Held in New Orleans, Louisiana (April 18-19, 1988).

Glass, Clinton C. "The Pipe Manipulator: A Complete Assessment of a New Idea in Construction Equipment Technology." MS thesis, University of Texas, December 1984.

O'Connor, James T, and Deborah J. Fisher. "Constructability for Semi-Automated Piping Construction: Research Progress." In The Fifth International Symposium on Robotics in Construction Held in Tokyo, Japan (June 6-8, 1988): 185-194.

Smith, Stephen D., Senior Project Engineer of Grove Manufacturing. Interview by author, 19 January \& 30 March 1988, Shady Grove, Pennsylvania.

Table 2 -- Total Piping Construction Savings From Field Operations Constructability Analysis by Erection Activities

\begin{tabular}{l|c|c|c} 
Step/Piping Erection Activities & $\begin{array}{l}\text { \% of Total Cycle } \\
\text { Time }\end{array}$ & $\begin{array}{l}\text { \% Cycle Time } \\
\text { Savings from } \\
\text { Time Lapse } \\
\text { Condition }\end{array}$ & $\begin{array}{l}\text { Savings (\% of } \\
\text { Total Cycle Time) }\end{array}$ \\
\hline $\begin{array}{l}\text { 1),2), 5) staging, gripping, } \\
\text { retuming }\end{array}$ & 21 & - & - \\
3) gross motion cycle time & 24 & 64 & 15 \\
3) gross motion idle time & 6 & 57 & 3 \\
$\begin{array}{l}\text { 4) fine motion + fine motion } \\
\text { idle time }\end{array}$ & 25 & - & - \\
6) respotting & 13 & - & - \\
7) jaw change & 8 & 75 & - \\
8) breaks & 3 & TOTAL & 24
\end{tabular}


Table 3 -- Total Piping Construction Savings From Field Operations

\begin{tabular}{|c|c|c|c|c|}
\hline Phase & $\begin{array}{l}\text { Constructability } \\
\text { Issue }\end{array}$ & $\begin{array}{c}\text { Constructability } \\
\text { Sub-Issue } \\
\end{array}$ & $\begin{array}{l}\text { avings of } \\
\text { Cycle Time } \\
\end{array}$ & $\begin{array}{c}\text { Affects Cherry } \\
\text { Picker/Manipulator }\end{array}$ \\
\hline \multirow[t]{3}{*}{$\begin{array}{l}\text { Field } \\
\text { Operations }\end{array}$} & Material Handling & $\begin{array}{l}\text { Manipulator/material } \\
\text { orientation }\end{array}$ & 4 & cherry picker/Manip \\
\hline & $\begin{array}{l}\text { Equipment/Tools } \\
\text { Capabilities }\end{array}$ & $\begin{array}{l}\text { operator location } \\
\text { booming vs driving } \\
\text { single vs multi-DOF controls }\end{array}$ & $\begin{array}{l}5 \\
3 \\
6\end{array}$ & $\begin{array}{l}\text { Manipulator } \\
\text { Manipulator } \\
\text { Manipulator }\end{array}$ \\
\hline & $\begin{array}{l}\text { Equipment/Tools } \\
\text { Configuration }\end{array}$ & $\begin{array}{l}\text { Manipulator Jaw configuration } \\
\text { (1 jaw size vs } 4 \text { ) }\end{array}$ & 6 & Manipulator \\
\hline
\end{tabular}

Table 4 -- Total Piping Construction Savings in Worker Hours Per Lift from Field Operations Constructability Analysis and Crew Balance

\begin{tabular}{|c|c|c|c|c|}
\hline & \multicolumn{2}{|c|}{ Manipulator } & \multicolumn{2}{|c|}{ Cherry Picker } \\
\hline & $\begin{array}{c}\text { [Glass 1984, 19, } \\
21,34]\end{array}$ & $\begin{array}{l}\text { Improved } \\
\text { (Table 3) }\end{array}$ & $\begin{array}{c}\text { [Glass 1984, 19, } \\
21,34]\end{array}$ & $\begin{array}{l}\text { Improved } \\
\text { (Table 3) }\end{array}$ \\
\hline $\begin{array}{l}\text { Horizontal pipe configuration (50\%) } \\
\text { Optimal constructability conditions } \\
\text { Crew balance savings }\end{array}$ & 1.20 & $\begin{array}{r}0.91 \text { ( } 24 \% \text { savings }) \\
\frac{-0.16}{0.75}(33 \% \text { savings })\end{array}$ & s) 0.58 & $\frac{0.56 \text { (4\% savings) }}{\frac{-}{0.56}}$ \\
\hline $\begin{array}{l}\text { ertical/bent pipe configuration ( } 50 \% \text { ) } \\
\text { ptimal constructability conditions } \\
\text { rew balance savings }\end{array}$ & 2.17 & $\begin{array}{r}1.65 \text { (24\% savings } \\
-0.47 \text { (33\% savings) } \\
\end{array}$ & 2.34 & $\begin{array}{l}2.25 \text { (4\% savings) } \\
- \\
\end{array}$ \\
\hline subtotal & & 1.18 & & 2.25 \\
\hline PRORATED TOTAL (50:50 split) & $\begin{array}{c}1.68 \text { worker } \\
\text { hours } \\
\text { per lift }\end{array}$ & $\begin{array}{l}0.96 \text { worker hours } \\
\text { per lift }\end{array}$ & $\begin{array}{l}1.46 \text { worker } \\
\text { hours } \\
\text { per lift }\end{array}$ & $\begin{array}{l}1.40 \text { worker hours } \\
\text { per lift }\end{array}$ \\
\hline
\end{tabular}

